\title{
PERHITUNGAN AKTUARIA MANFAAT PENSIUN-NORMAL SUKU BUNGA VASICEK MENGGUNAKAN METODE ENTRY AGE NORMAL
}

\author{
Wimas Astari Yuda ${ }^{1 \S}$, I Nyoman Widana ${ }^{2}$ I Wayan Sumarjaya ${ }^{3}$ \\ ${ }^{1}$ Program Studi Matematika, Fakultas MIPA - UniversitasUdayana [Email: wimasastari@gmail.com] \\ ${ }^{2}$ Program Studi Matematika, Fakultas MIPA - UniversitasUdayana [Email:nwidana @ yahoo.com] \\ ${ }^{3}$ Program Studi Matematika, Fakultas MIPA - Universitas Udayana [Email:sumarjaya@unud.ac.id] \\ ${ }^{\S}$ Corresponding Author
}

\begin{abstract}
Vasicek is one of the stochastic interest rate models that can figure out fluctuating interest rate movements. This study aims to determine the actuarial calculation of normal contributions and actuarial liability with Vasicek interest rates using entry age normal (EAN) method. Based on the calculation of normal contribution and actuarial liability with Vasicek interest rate using this method for normal retirement age of 56 years obtained a smaller value than using constant interest rate.
\end{abstract}

Keywords: Actuarial calculation, entry age normal, pension insurance, vasicek.

\section{PENDAhUluan}

Program pensiun merupakan program dalam mempersiapkan jaminan penghasilan karyawan pada masa pensiun dengan cara membayarkan sejumlah iuran secara rutin selama karyawan aktif bekerja. Perusahaan memiliki kewajiban moral untuk memberikan rasa aman kepada karyawannya atas jaminan penghasilan pada masa yang akan datang saat karyawan tersebut mencapai usia pensiun. Perusahaan dapat memasukkan program pensiun sebagai bagian dari usaha pengadaan jaminan penghasilan pada masa mendatang kepada karyawan saat masuk masa pensiun (Rivai dkk., 2007).

Pelaksanaan program pensiun di Indonesia dijalankan oleh suatu badan hukum yaitu Dana Pensiun. Dana Pensiun merupakan suatu badan hukum yang berdiri sendiri dan terpisah dari perusahaan serta memiliki tugas untuk mengelola dan menjalankan program pensiun sesuai dengan peraturan perundang-undangan di Indonesia.

Program pensiun manfaat pasti adalah program pensiun yang besar manfaatnya telah ditetapkan sedangkan besarnya iuran pemberi kerja (kewajiban aktuaria) dari waktu ke waktu tidak pasti jumlahnya, bergantung dari kecukupan dana untuk memenuhi kewajiban dalam membayar manfaat pensiun. Kewajiban aktuaria merupakan nilai sekarang pembayaran manfaat pensiun yang akan diberikan Dana Pensiun kepada karyawan sampai terpenuhinya seluruh manfaat pensiun. Nilai aktuaria dari sebagian manfaat pensiun total yang mengacu pada tahun valuasi, dengan asumsi valuasi pada saat awal tahun disebut iuran normal.

Salah satu metode yang merupakan bagian dari metode pembebanan aktuaria (actuarial cost method) untuk menghitung iuran normal dan kewajiban aktuaria adalah entry age normal (EAN). Metode EAN adalah metode yang menekankan pada proyeksi manfaat pensiun ketika mencapai usia pensiun dimulai saat usia masuk kerja.

Penelitian Oktiani (2013) terkait perhitungan aktuaria untuk manfaat pensiunnormal menggunakan metode projected unit credit (PUC) dan EAN dengan asumsi tingkat suku bunga sebesar $10 \%$. Hasil penelitian menunjukkan bahwa iuran normal yang dihitung dengan menggunakan metode PUC besarnya meningkat setiap tahun tetapi jika menggunakan 
metode EAN iuran normalnya konstan setiap tahun. Adam (2014) juga melakukan penelitian menggunakan metode EAN untuk perhitungan biaya normal program pensiun dengan bunga tetap $7 \%$ per tahun. Hasilnya menunjukkan bahwa semakin lama masa kerja seseorang maka semakin besar manfaat yang akan diperoleh.

Penelitian tersebut seluruhnya menggunakan asumsi tingkat suku bunga konstan. Tetapi pada kasus yang lebih realistis, tingkat suku bunga pasti mengalami perubahan sesuai dengan waktu (stokastik). Oleh karena itu, dalam penelitian ini perhitungan aktuaria dilakukan menggunakan model suku bunga stokastik yaitu suku bunga Vasicek. Suku bunga model Vasicek adalah suatu metode pemodelan terhadap pergerakan suku bunga sebagai faktor resiko pasar dan waktu (Zeytun dan Gupta, 2007).

Dengan demikian tujuan dari penelitian adalah:

1. mengetahui hasil perhitungan manfaat pensiun normal;

2. mengetahui hasil perhitungan iuran normal dan kewajiban aktuaria dengan suku bunga konstan menggunakan metode EAN; dan

3. mengetahui hasil perhitungan iuran normal dan kewajiban aktuaria dengan suku bunga model Vasicek menggunakan metode EAN.

Selanjutnya dibahas komponen-komponen yang diperlukan dalam perhitungan iuran normal dan kewajiban aktuaria suku bunga konstan dan Vasicek menggunakan metode EAN.

Perhitungan bunga yang digunakan dalam penentuan besarnya iuran normal pada program pensiun adalah bunga majemuk. Bunga majemuk merupakan suatu perhitungan bunga yang besar pokok jangka investasi selanjutnya adalah besar pokok sebelumnya ditambah dengan besar bunga yang diperoleh (Futami, 1993). Dalam bunga majemuk didefinisikan suatu fungsi $v$ sebagai berikut:

$$
v=\frac{1}{1+i}
$$

dengan $v$ adalah nilai sekarang dari pembayaran sebesar 1 yang dilakukan 1 tahun kemudian dan $i$ adalah tingkat suku bunga.
Anuitas adalah suatu rangkaian pembayaran dalam jumlah tertentu, yang dilakukan setiap selang dan jangka waktu tertentu, secara berkelanjutan (Futami, 1993). Nilai tunai anuitas hidup dinotasikan dengan $\ddot{a}_{x}$ dan ditulis sebagai berikut:

$$
\ddot{a}_{x}=\sum_{k=0}^{\infty} v_{k}^{k} p_{x}
$$

Sedangkan Actuarial Present Value dari anuitas hidup berjangka $n$ tahun dinotasikan dengan $\ddot{a}_{x: \bar{n}]}$ dan didefinisikan sebagai (Dickson dkk., 2009):

$$
\ddot{a}_{x: \bar{n}]}=\sum_{k=0}^{n-1} v^{k} \cdot{ }_{k} p_{x}
$$

dengan ${ }_{k} p_{x}$ adalah peluang seseorang berusia $x$ hidup dalam masa $k$ tahun mendatang.

Manfaat pensiun adalah pembayaran berkala yang dibayarkan kepada peserta pada saat dan dengan cara yang ditetapkan dalam peraturan dana pensiun. Pada penelitian ini digunakan jenis final salary plan dalam menghitung manfaat pensiun. Final salary plan merupakan jenis fungsi manfaat yang besar maanfaat pensiunnya dihitung berdasarkan gaji terakhir peserta sebelum memasuki usia pensiun dan dinotasikan sebagai (Dickson dkk., 2009):

$$
B_{r}=k(r-e) S_{r-1}
$$

dengan $k$ adalah proporsi gaji untuk manfaat pensiun dan $S_{r-1}$ adalah besarnya gaji satu tahun sebelum pensiun.

Present Value of Future Benefit (PVFB) adalah nilai sekarang dari manfaat pensiun yang akan diterima pada masa mendatang. Nilai sekarang manfaat pensiun untuk peserta usia $x$ sebelum pensiun dengan asumsi manfaat pensiun yang akan dibayarkan dalam bentuk anuitas sebesar $B_{r}$ didefinisikan sebagai (Winklevoss, 1993):

$$
\begin{gathered}
(P V F B)_{x}=B_{r} \cdot v^{r-x}{ }_{r-x} P_{x} \cdot \ddot{a}_{r}, \\
e \leq x<r
\end{gathered}
$$

Sedangkan Present Value of Future Normal Cost (PVFNC) adalah nilai sekarang dari iuran normal yang dibayarkan oleh peserta dalam bentuk anuitas. Secara sistematis PVFNC untuk peserta usia $x$ dan pensiun pada usia $r$ dinotasikan sebagai berikut: 


$$
(P V F N C)_{x}=\sum_{t=x}^{r-1}(N C) \cdot v^{t-x}{ }_{t-x} P_{x}
$$

Model Vasicek adalah suatu metode pemodelan terhadap pergerakan suku bunga sebagai faktor risiko pasar dan waktu yang memiliki ciri khusus yaitu tingkat suku bunga akan cenderung kembali ke tingkat suku bunga rata-rata setelah mengalami penurunan dan peningkatan. Suku bunga model Vasicek nilai suku bunga menggunakan persamaan berikut (Winklevoss, 1993):

$$
\begin{gathered}
d r(t)=\kappa[\theta-r(t)] d t+\sigma d W(t), \\
r(0)=r_{0}
\end{gathered}
$$

Misalkan $P(k)$ menyatakan ekspektasi dari nilai tunai pembayaran sebesar 1 unit pada saat $k$, untuk tingkat suku bunga yang mengikuti model Vasicek, maka $P(k)$ dituliskan sebagai

$$
\begin{aligned}
P(k)=\exp ( & \left(\theta-\frac{\sigma^{2}}{2 \mathrm{~K}^{2}}\right)(B(k)-k) \\
& -\frac{\sigma^{2}}{4 \mathrm{k}} B(k)^{2} \\
& -r(0) B(k))
\end{aligned}
$$

dengan

$$
B(k)=\frac{1-\exp (-\mathrm{k} k)}{\mathrm{K}}
$$

Entry Age Normal Cost (EAN) adalah jumlah dari seluruh tingkat kontribusi saat usia mulai bekerja sedemikian sehingga nilai sekarang dari iuran normal yang akan datang sama dengan nilai sekarang dari manfaat yang akan datang. Konsep dasar metode EAN dapat dinotasikan sebagai (Aitken, 1994):

$$
(P V F N C)_{e}=(P V F B)_{e}
$$

Berdasarkan persamaan (5) dan (6), iuran normal (normal cost) dapat dirumuskan sebagai:

$$
(N C)_{x}=N C=\frac{B_{r} \cdot v^{r-e} \cdot r-e}{P_{e} \cdot \ddot{a}_{r}}
$$

Kewajiban aktuaria (accrued liability) adalah nilai sekarang dari manfaat yang akan datang dikurangi dengan nilai sekarang dari iuran normal yang akan datang. . Berdasarkan pengertian, kewajiban aktuaria (accrued liability) dinotasikan sebagai:

$$
(A L)_{x}=(P V F B)_{x}-(P V F N C)_{x}
$$

Berdasarkan persamaan (5), (6), dan (11), kewajiban aktuaria (accrued liability) dapat dirumuskan sebagai berikut:

$$
\begin{aligned}
(A L)_{x}= & B_{r} \cdot v^{r-x}{ }_{r-x} P_{x} \cdot \ddot{a}_{r} \\
& -\frac{B_{r} \cdot v^{r-e}{ }_{r-e} P_{e} \cdot \ddot{a}_{r}}{\ddot{a}_{\bar{e}: r-e}} \cdot \ddot{a}_{\overline{x: r-x} \mid}
\end{aligned}
$$

\section{METODE PENELITIAN}

Penelitian ini menggunakan data sekunder, yaitu data Tabel Mortalita Taspen 2012. Pengolahan data pada penelitian ini menggunakan software Microsoft Excel dan R i386 3.3.1.

Langkah-langkah yang dilakukan dalam penelitian ini adalah sebagai berikut:

1. Mengumpulkan rata-rata suku bunga Bank Indonesia pada tahun 2006-2016 di alamat http://www.bi.go.id/en/moneter/bi-rate/data.

2. Mengestimasi suku bunga Vasicek dengan metode Maximum Likelihood Estimator.

3. Mengkonstruksi rumus perhitungan iuran normal dan kewajiban aktuaria dengan suku bunga Vasicek.

4. Menentukan besar manfaat pensiun berdasarkan asumsi gaji terakhir.

5. Menghitung nilai tunai anuitas hidup suku bunga konstan dan nilai tunai anuitas hidup suku bunga Vasicek.

6. Menghitung nilai tunai anuitas hidup berjangka suku bunga konstan dan nilai tunai anuitas hidup berjangka suku bunga Vasicek.

7. Melakukan simulasi perhitungan iuran normal dan kewajiban aktuaria dengan langkah-langkah: (a) Menghitung besar iuran normal suku bunga konstan dengan metode EAN; (b) Menghitung besar iuran normal suku bunga Vasicek menggunakan metode EAN; (c) Menghitung besar kewajiban aktuaria suku bunga konstan dengan metode EAN; (d) Menghitung besar kewajiban aktuaria suku bunga Vasicek dengan metode EAN. 


\section{HASIL DAN PEMBAHASAN}

Dalam menghitung nilai iuran normal dan kewajiban aktuaria suku bunga model Vasicek, terlebih dahulu dilakukan estimasi parameter $\mathrm{\kappa}$, $\theta$, dan $\sigma$ menggunakan persamaan (7) dan data rata-rata tingkat suku bunga tahunan Bank Indonesia (BI Rate). Data rata-rata suku bunga tahunan Bank Indonesia secara rinci dapat dilihat pada Tabel 1.

Tabel 1. Rata-rata Tingkat Suku Bunga Tahunan Bank Indonesia tahun 2006-2016

\begin{tabular}{|c|c|}
\hline Tahun & Rata-Rata BI Rate (\%) \\
\hline 2006 & $11,83 \%$ \\
\hline 2007 & $8,60 \%$ \\
\hline 2008 & $8,67 \%$ \\
\hline 2009 & $7,15 \%$ \\
\hline 2010 & $6,50 \%$ \\
\hline 2011 & $6,58 \%$ \\
\hline 2012 & $5,77 \%$ \\
\hline 2013 & $6,46 \%$ \\
\hline 2014 & $7,53 \%$ \\
\hline 2015 & $7,52 \%$ \\
\hline 2016 & $7,25 \%$ \\
\hline
\end{tabular}

Estimasi parameter menggunakan metode Maximum Likelihood Estimator dengan bantuan software R i386 3.3.1 menghasilkan estimasi parameter yang secara rinci dapat dilihat pada Tabel 2.

Tabel 2. Hasil Estimasi Parameter Suku Bunga Vasicek

\begin{tabular}{|c|c|}
\hline Coefficients & Estimate \\
\hline $\mathrm{K}$ & 0,5175945 \\
\hline$\theta$ & 0,06575811 \\
\hline$\sigma$ & 0,006215903 \\
\hline
\end{tabular}

Hasil estimasi parameter $\mathrm{\kappa}, \theta$ dan $\sigma$ selanjutnya disubtitusikan ke dalam persamaan (8) dan (9), dituliskan sebagai:

$$
\begin{aligned}
& P(k) \\
& =\exp ((0,06575811 \\
& \left.-\frac{(0,006215903)^{2}}{2(0,5175945)^{2}}\right)(B(k)-k) \\
& -\frac{(0,006215903)^{2}}{4(0,5175945)} B(k)^{2} \\
& -r(0) B(k))
\end{aligned}
$$

dengan

$$
B(k)=\frac{1-\exp (-(0,5175945) k)}{(0,5175945)}
$$

Langkah berikutnya adalah mengkonstruksi rumus perhitungan iuran normal dan kewajiban aktuaria menggunakan model suku bunga Vasicek. Berdasarkan persamaan (2) dan (8), nilai tunai anuitas hidup menggunakan suku bunga Vasicek dapat dinyatakan sebagai:

$$
\ddot{a_{x}}=\sum_{k=0}^{\infty} P(k){ }_{k} p_{x}
$$

Nilai tunai anuitas hidup berjangka suku bunga Vasicek dapat diperoleh berdasarkan persamaan (3) dan (8) yaitu:

$$
\ddot{a}_{x: \overline{n\rceil}}=\sum_{k=0}^{n-1} P(k){ }_{k} p_{x}
$$

Selanjutnya dengan mensubstitusi persamaan (16) dan (17) ke persamaan (11) diperoleh persamaan iuran normal suku bunga Vasicek sebagai berikut:

$(N C)_{x}$

$$
=\frac{B_{r} \cdot P(r-e) \cdot_{r-e} P_{e} \cdot \sum_{k=0}^{\infty} P(k)_{k} p_{r}}{\sum_{k=0}^{r-e-1} P(k){ }_{k} p_{e}}
$$

Sementara itu, untuk persamaan kewajiban aktuaria dengan suku bunga Vasicek diperoleh dengan mensubtitusi persamaan (16) dan (17) ke persamaan (13) yang dapat ditulis sebagai: 


$$
\begin{aligned}
& (A L)_{x} \\
& =B_{r} \cdot P(r-x)_{\cdot r-x} P_{x} \cdot \sum_{k=0}^{\infty} P(k)_{k} p_{r} \\
& \quad-\frac{B_{r} \cdot P(r-e)_{\cdot r-e} P_{e} \cdot \sum_{k=0}^{\infty} P(k)_{k} p_{r}}{\sum_{k=0}^{r-e-1} P(k)_{k} p_{e}} \\
& \quad \cdot \sum_{k=0}^{r-x-1} P(k)_{k} p_{x}
\end{aligned}
$$

Dalam penelitian ini, asumsi gaji yang diterima selama setahun terakhir $\left(S_{r-1}\right)$ adalah sebesar Rp 24.622.548,-. Selanjutnya dihitung besar manfaat pensiun untuk peserta asuransi dengan usia masuk kerja 22, 24, 26, 28 dan 30 tahun serta usia pensiun 56 tahun dengan proporsi dari gaji dari manfaat pensiun $(k)$ sebesar 2,5\%. Besar manfaat pensiun berdasarkan asumsi gaji terakhir dapat dihitung berdasarkan persamaan (4). Secara ringkas nilainilai manfaat pensiun dapat dilihat pada Tabel 3 .

Tabel 3. Nilai Manfaat Pensiun $(B r)$ saat usia masuk kerja $(e)$

\begin{tabular}{|c|c|}
\hline $\begin{array}{c}\text { Usia Masuk Kerja } \\
\text { (tahun) }\end{array}$ & $\begin{array}{c}\text { Manfaat Pensiun } \\
(\mathrm{Rp})\end{array}$ \\
\hline 22 & $20.929 .165,8$ \\
\hline 24 & $19.698 .038,4$ \\
\hline 26 & $18.466 .911,0$ \\
\hline 28 & $17.235 .783,6$ \\
\hline 30 & $16.004 .656,2$ \\
\hline
\end{tabular}

Selanjutnya nilai tunai anuitas hidup dan nilai tunai anuitas hidup berjangka dihitung untuk peserta asuransi dengan usia pensiun 56 tahun berdasarkan nilai-nilai peluang Tabel Mortalita Taspen 2012 (TMT 2012). Berdasarkan persamaan (2) nilai tunai anuitas hidup suku bunga konstan dapat dihitung sebagai berikut.

$$
\begin{aligned}
\ddot{a_{56}} & =\sum_{k=0}^{\infty} v^{k}{ }_{k} p_{56} \\
& =v^{0} \cdot{ }_{0} p_{56}+v^{1} \cdot{ }_{1} p_{56}+\ldots+v^{55} \cdot{ }_{55} p_{56} \\
& =1+0,95077507+\cdots \\
& \quad+0,0000000152456 \\
& =14,40476392
\end{aligned}
$$

Sedangkan nilai anuitas hidup suku bunga Vasicek diperoleh menggunakan persamaan (16) dengan terlebih dahulu menghitung nilai pada persamaan (14). Nilai suku bunga awal yang digunakan adalah $4,25 \%\left(r_{0}=0,0425\right)$.

$$
\begin{aligned}
& a_{56}=P(0){ }_{0} p_{56}+P(1){ }_{1} p_{56}+\ldots \\
& +P(55)_{55} p_{56} \\
& =1,0000000000000+ \\
& 0,9451208300000+\cdots+ \\
& 0,0000000424419 \\
& =11,9341983500
\end{aligned}
$$

Sehingga diperoleh nilai tunai anuitas hidup suku bunga Vasicek untuk peserta dengan usia pensiun 56 tahun sebesar 11,9341983500.

Untuk nilai tunai anuitas hidup berjangka suku bunga konstan dihitung menggunakan persamaan (3). Sedangkan nilai tunai anuitas hidup berjangka suku bunga Vasicek dihitung menggunakan persamaan (17) dengan terlebih dahulu menghitung nilai pada persamaan (14). Seluruh perhitungan dilakukan terhadap peserta asuransi dengan usia masuk kerja 22, 24, 26, 28, dan 30. Secara ringkas nilai-nilai tunai anuitas hidup berjangka suku bunga konstan dan suku bunga Vasicek dapat dilihat pada Tabel 4.

Tabel 4. Nilai Tunai Anuitas Hidup Berjangka Suku Bunga Konstan dan Vasicek

\begin{tabular}{|c|c|c|}
\hline $\begin{array}{c}\text { Usia Masuk } \\
\text { Kerja } \\
\text { (tahun) }\end{array}$ & $\begin{array}{c}\text { Suku Bunga } \\
\text { Konstan }\end{array}$ & $\begin{array}{c}\text { Suku Bunga } \\
\text { Vasicek }\end{array}$ \\
\hline 22 & 18,26444600 & 14,39493861 \\
\hline 24 & 17,73879148 & 14,13581648 \\
\hline 26 & 17,17024008 & 13,84272883 \\
\hline 28 & 16,55538864 & 13,51124000 \\
\hline 30 & 15,89054420 & 13,13631292 \\
\hline
\end{tabular}

Simulasi perhitungan iuran normal dan kewajiban aktuaria dilakukan untuk peserta asuransi dengan usia masuk kerja 22, 24, 26, 28, dan 30 tahun dengan tahun valuasi yang sama yaitu 35 tahun. Suku bunga awal yang digunakan sebesar $11.83 \% \quad\left(r_{0}=0,11833\right)$ dengan usia pensiun 56 tahun berdasarkan nilainilai peluang Tabel Mortalita Taspen 2012 (TMT 2012).

Perhitungan iuran normal suku bunga konstan metode EAN dilakukan berdasarkan persamaan (11). Sebagai ilustrasi, hasil 
perhitungan iuran normal suku bunga konstan metode entry age normal usia masuk kerja 22 tahun adalah sebagai berikut:

$$
\begin{aligned}
& (N C)_{35}=N C \\
& =\frac{B_{56} \cdot v^{56-22} \cdot 56-22}{\ddot{a}_{22: 56-22} P_{22} \cdot \ddot{a}_{56}} \\
& =(20929166 \times 0,24289235 \times 0,910818928 \\
& \quad \times 14,40476392) / 18,264446 \\
& =3651719,814 \quad
\end{aligned}
$$

Dengan cara yang sama, dapat dihitung besar iuran normal suku bunga konstan metode entry age normal untuk usia masuk kerja 24, 26, 28, dan 30 tahun. Hasil seluruh perhitungan iuran normal secara ringkas dapat dilihat pada Tabel 5.

Tabel 5. Besar Iuran Normal Suku Bunga Konstan Metode Entry Age Normal

\begin{tabular}{|c|c|}
\hline $\begin{array}{c}\text { Usia Masuk Kerja } \\
\text { (tahun) }\end{array}$ & Iuran Normal (Rp) \\
\hline 22 & $3.651 .719,814$ \\
\hline 24 & $3.849 .783,695$ \\
\hline 26 & $4.057 .157,007$ \\
\hline 28 & $4.274 .236,535$ \\
\hline 30 & $4.501 .445,036$ \\
\hline
\end{tabular}

Perhitungan iuran normal suku bunga Vasicek metode EAN dilakukan berdasarkan persamaan (18). Sebagai ilustrasi, berikut dihitung iuran normal suku bunga Vasicek metode entry age normal untuk usia masuk kerja 22 tahun.

$$
\begin{aligned}
& (N C)_{35}=N C \\
& =\frac{B_{56} \cdot P(56-22) \cdot{ }_{56-22} P_{22} \cdot \sum_{k=0}^{\infty} P(k)_{k} p_{56}}{\sum_{k=0}^{56-22-1} P(k){ }_{k} p_{22}} \\
& =(20929166 \times 0,112081583 \times 0,91081893 \\
& \times 11,93419835) / 14,3949386 \\
& =1771482,955
\end{aligned}
$$

Hasil seluruh perhitungan iuran normal secara ringkas dapat dilihat pada Tabel 6 .
Tabel 6. Besar Iuran Normal Suku Bunga Vasicek Metode Entry Age Normal

\begin{tabular}{|c|c|}
\hline $\begin{array}{c}\text { Usia Masuk Kerja } \\
\text { (tahun) }\end{array}$ & Iuran Normal (Rp) \\
\hline 22 & $1.771 .482,955$ \\
\hline 24 & $1.937 .978,662$ \\
\hline 26 & $2.118 .302,651$ \\
\hline 28 & $2.313 .216,402$ \\
\hline 30 & $2.523 .671,147$ \\
\hline
\end{tabular}

Sedangkan perhitungan kewajiban aktuaria suku bunga konstan metode EAN dilakukan berdasarkan persamaan (13). Sebagai ilustrasi, hasil perhitungan kewajiban aktuaria suku bunga konstan metode entry age normal usia masuk kerja 22 tahun adalah sebagai berikut:

$(A L)_{35}$

$$
\begin{aligned}
& =B_{56} \cdot v^{56-35} \cdot{ }_{56-35} P_{35} \cdot \ddot{a}_{56} \\
& -\frac{B_{56} \cdot v^{56-22} \cdot{ }_{56-22} P_{22} \cdot \ddot{a}_{56}}{\ddot{a}_{\overline{22: 56-22} \mid}} \cdot \ddot{a}_{35: 56-35} \\
& =(20929166 \times 0,41725607 \times 0,92083346 \\
& \times 14,40476392) \\
& -(3651719,814 \times 13,98236844) \\
& =64775846,79
\end{aligned}
$$

Dengan cara yang sama, dapat dihitung besar kewajiban aktuaria suku bunga konstan metode EAN untuk usia masuk kerja 24, 26, 28, dan 30 tahun. Hasil seluruh perhitungan iuran normal secara ringkas dapat dilihat pada Tabel 7.

Tabel 7. Besar Kewajiban Aktuaria Suku Bunga Konstan Metode Entry Age Normal

\begin{tabular}{|c|c|}
\hline $\begin{array}{c}\text { Usia Masuk } \\
\text { Kerja (tahun) }\end{array}$ & Kewajiban Aktuaria (Rp) \\
\hline 22 & $64.775 .846,79$ \\
\hline 24 & $55.192 .588,37$ \\
\hline 26 & $45.479 .163,17$ \\
\hline 28 & $35.630 .022,08$ \\
\hline 30 & $25.639 .253,95$ \\
\hline
\end{tabular}

Kewajiban aktuaria suku bunga Vasicek metode entry age normal ditentukan menggunakan persamaan (19). Sebagai ilustrasi, berikut dihitung kewajiban aktuaria suku bunga Vasicek 
metode entry age normal untuk usia masuk kerja 22 tahun.

$$
\begin{aligned}
& (A L)_{35} \\
& =B_{56} \cdot P(56-35) \cdot{ }_{56-35} P_{35} \cdot \sum_{k=0}^{\infty} P(k){ }_{k} p_{56} \\
& -\frac{B_{56} \cdot P(56-22) \cdot 56-22}{\sum_{k 2}^{56-22-1} P(k){ }_{k} p_{22}} \\
& \quad \cdot \sum_{k=0}^{56-35-1} P(k){ }_{k} p_{35} \\
& =(20929166 \times 0,263260534 \\
& \times 0,92083346 \times 11,93419835) \\
& -(20929166 \times 0,263260534 \times 0,92083346 \\
& \times 11,93419835)=39346291,05
\end{aligned}
$$

Hasil seluruh perhitungan kewajiban aktuaria secara ringkas dapat dilihat pada Tabel 8.

Tabel 8. Besar Kewajiban Aktuaria Suku Bunga Vasicek Metode Entry Age Normal

\begin{tabular}{|c|c|}
\hline $\begin{array}{c}\text { Usia Masuk Kerja } \\
\text { (tahun) }\end{array}$ & Kewajiban Aktuaria (Rp) \\
\hline 22 & $39.346 .291,05$ \\
\hline 24 & $33.791 .705,94$ \\
\hline 26 & $28.071 .606,53$ \\
\hline 28 & $22.176 .877,86$ \\
\hline 30 & $16.096 .134,36$ \\
\hline
\end{tabular}

\section{SIMPULAN DAN SARAN}

\section{A. Simpulan Penelitian}

Berdasarkan hasil dan pembahasan, manfaat pensiun mengalami penurunan seiring dengan bertambahnya usia masuk kerja. Nilai iuran normal suku bunga konstan dan suku bunga Vasicek menggunakan metode Entry Age Normal (EAN) mengalami kenaikan ketika usia masuk kerja semakin bertambah. Sebaliknya nilai kewajiban aktuaria suku bunga konstan dan suku bunga Vasicek mengalami penurunan ketika usia masuk kerja semakin bertambah. Hasil tersebut juga menunjukkan bahwa iuran normal dan kewajiban aktuaria dengan menggunakan suku bunga Vasicek memiliki nilai lebih kecil dari pada iuran normal dan kewajiban aktuaria yang menggunakan suku bunga konstan. Artinya, cadangan manfaat pensiun-normal yang harus disediakan perusahaan dengan suku bunga Vasicek lebih kecil dibandingkan penggunaan suku bunga konstan.

\section{B. Saran}

Pada penelitian ini penulis menggunakan metode Entry Age Normal suku bunga stokastik model Vasicek dalam perhitungan aktuaria manfaat pensiun-normal, disarankan untuk penelitian selanjutnya dilakukan perbandingan nilai perhitungan aktuaria menggunakan suku bunga stokastik model yang lain seperti CIR.

\section{DAFTAR PUSTAKA}

Adam, F. F., 2014. Perhitungan Biaya Normal Program Pensiun Usia Normal dengan Metode Entry Age Normal (Percent Dollar). Jurnal Vokasi Indonesia, Volume 2, No 1, pp.22-28.

Aitken, W. H., 1994. A Problem Solving Approach to Pension Funding and Valuation. Winsted: ACTEX Publications.

Dickson, D. C., Hardy, M. R. \& Waters, H. R., 2009. Actuarial Mathematics for Life Contingent Risk. New York: Cambridge University Press.

Futami, T., 1993. Matematika Asuransi Jiwa, Bagian I. Tokyo: Oriental Life Insurance Cultural Development Center.

Oktiani, I., 2013. Perhitungan Aktuaria untuk Manfaat Pensiun-Normal Menggunakan Metode Projected Unit Credit dan Entry Age Normal. Bogor: Institut Pertanian Bogor.

Rivai, V., Veithzal, A. P., \& Idroes, F. N., 2007. Bank and Financial Institution Management. Jakarta: PT. Raja Grafindo Persada.

Winklevoss, H. E., 1993. Pension Mathematics with Numerical Illustration. Philadelphia: University of Pennsylvania Press.

Zeytun, S., \& Gupta, A., 2007. A Comparative Study of the Vasicek and the CIR Model of the Short Rate. Germany: Fraunhofer Institute Techno-und Wirtschaftsmathematik 